\title{
HEMATOCRIT VALUE ON INTENSIVE CARE UNIT ENTRY INFLUENCES THE FREQUENCY OF Q-WAVE MYOCARDIAL INFARCTION AFTER CORONARY ARTERY BYPASS GRAFTING
}

Bruce D. Spiess, MD

Catherine Ley, $\mathrm{PhD}$

Simon C. Body, MB, ChB

Lawrence C. Siegel, MD

E. Price Stover, MD

Rosemarie Maddi, MD

Michael D'Ambra, MD

Uday Jain, MD

Fong Liu, MSPH

Ahvie Herskowitz, MD

Dennis T. Mangano, $\mathrm{PhD}, \mathrm{MD}$

Jack Levin, MD

The Institutions of the Multicenter Study of Perioperative Ischemia (McSPI) Research Group
Objectives: No data exist regarding "the best" hematocrit value after coronary artery bypass graft surgery. Transfusion practice varies, because neither an optimal hematocrit value nor a uniform transfusion trigger criterion has been determined. Methods: To investigate the optimal hematocrit value, we studied 2202 patients undergoing coronary bypass. The hematocrit value on entry into the intensive care unit (IHCT) was categorized into three groups: high $(\geq 34 \%)$, medium (25\% to 33\%), and low ( $\leq 24 \%)$. Characteristics and adverse events (outcomes) were compared, and the effect of IHCT on the risk of myocardial infarction was determined by logistic regression. Results: High IHCT $(\geq 34 \%)$ was associated with an increased rate of myocardial infarction $(8.3 \%$ vs $5.5 \%$ vs $3.6 \% ; p \leq 0.03$, high, medium vs low) and with more severe left ventricular dysfunction (11.7\% vs $7.4 \%$ and $5.7 \% ; p=0.006$, high, medium vs low). Mortality rate increased with higher IHCT when all the high-risk subgroups were combined $(8.6 \%$ vs $4.5 \%$ vs $3.2 \% ; p<0.001$, high, medium vs low). By multivariate analysis, IHCT remained the most significant predictor of adverse outcomes (relative risk high vs low $2.22,95 \%$ confidence interval: 1.04 to 4.76 ). No characteristic, event, medication, or transfusion therapy confounded the relationship between IHCT and outcome. Conclusion: High IHCT is associated with a higher rate of myocardial infarction and is an independent predictor of infarction. On the basis of the risk of myocardial infarction, there is no rationale for transfusion to an arbitrary level after coronary artery bypass grafting. (J Thorac Cardiovasc Surg 1998;116:460-7)
N o data exist regarding the "best" hematocrit (HCT) value after cardiopulmonary bypass. Clinicians have assumed that anemia increases the risk of myocardial ischemia after coronary artery bypass graft (CABG) operations. Several recent studies have suggested that there might not be an association between anemia and morbidity after CABG. ${ }^{1,2}$ Therefore no safe lower limit of HCT has been established, yet the risks of transfusion are well

From the Department of Anesthesiology, University of Washington, Seattle, Wash. (B.D.S.); The Ischemia Research and Education Foundation, San Francisco, Calif. (C.L., F.L., A.H.); the Department of Anesthesia, Brigham and Women's Hospital, Boston, Mass. (S.B., R.M.); the Department of Anesthesiology, Stanford University Medical Center, Stanford, Calif. (L.S., P.S.); the Department of Anesthesiology, Massachusetts General Hospital, Boston, Mass. (M.D'A.); and the Departments of Anesthesiology and Laboratory Medicine, Veterans Administration Medical Center, San Francisco, Calif. (U.J., D.T.M., J.L.).

See Appendixes 1 and 2 for list of $M C S P I$ investigators and central analysis group members. delineated. ${ }^{3}$ A wide variability exists in blood use for CABG operations. ${ }^{4,5}$ The difference in transfusion practice is probably a reflection of the lack of adequate data regarding morbidity and mortality risks for HCT levels after CABG. Any new data regarding relative outcome risks and HCT may have an impact on national blood use and costs (15\% to $20 \%$ of blood is used in cardiopulmonary bypass). ${ }^{6-8}$

In the patient undergoing $\mathrm{CABG}$, the highest risk

Supported by a grant from the Ischemia Research and Education Foundation.

These data were presented in part at the Annual Meeting of the Society of Cardiothoracic Anesthesiologists in May 1995 in Philadelphia, $\mathrm{Pa}$.

Received for publication Sept. 16, 1997; rcvisions requested Jan. 13, 1998; revisions received March 4, 1998; accepted for publication March 25; 1998.

Address for reprints: Bruce D. Spiess, MD, University of Washington, Department of Anesthesiology, Box 35640, Seattle, WA 98195.

$12 / 1 / 90673$ 
Table I. Distribution of preoperative and intraoperative characteristics of patients in the three IHCT groups

\begin{tabular}{|c|c|c|c|c|}
\hline & $\begin{array}{c}H C T \leq 24 \% \\
(n=248) \\
\end{array}$ & $\begin{array}{c}H C T 25 \%-33 \% \\
\quad(n=1544)\end{array}$ & $\begin{array}{c}H C T \geq 34 \% \\
(n=410) \\
\end{array}$ & \\
\hline Characteristic & $\%(n)$ & $\%(n)$ & $\%(n)$ & $p$ Value \\
\hline Age (yr; mean, SD) & $64.3 \pm 10.2$ & $64.8 \pm 10.1$ & $63.7 \pm 11.1$ & 0.13 \\
\hline BSA $\left(\mathrm{m}^{2} ;\right.$ mean, SD) & $1.86 \pm 0.20$ & $1.93 \pm 0.21$ & $1.93 \pm 0.24$ & $<0.001^{*}$ \\
\hline Female gender & $26(65)$ & $23(356)$ & $25(104)$ & 0.40 \\
\hline History of smoking & $62(150)$ & $67(1,014)$ & $70(285)$ & 0.06 \\
\hline History of COPD & $170(42)$ & $18.9(293)$ & $19.5(80)$ & 0.47 \\
\hline History of anemia & $10(25)$ & $7(107)$ & $5(19)$ & 0.03 \\
\hline History of unstable angina & $45(109)$ & $45(695)$ & $48(193)$ & 0.69 \\
\hline History of MI & $52(127)$ & $54(820)$ & $54(218)$ & 0.78 \\
\hline History of $\mathrm{CHF}$ & $32(80)$ & $32(484)$ & $30(120)$ & 0.71 \\
\hline Prior CABG & $9(23)$ & $12(185)$ & $16(64)$ & $0.04 \dagger$ \\
\hline History of thrombolysis $\$$ & $4(11)$ & $6(92)$ & $4(15)$ & 0.15 \\
\hline History of aspirin use $\$$ & $67(165)$ & $64(991)$ & $59(243)$ & 0.11 \\
\hline Emergency surgery & $19(47)$ & $22(333)$ & $23(96)$ & 0.40 \\
\hline Valve or other surgery & $18(44)$ & $15(235)$ & $14(58)$ & 0.46 \\
\hline Bypass time (min; mean, SD) & $113 \pm 49$ & $113 \pm 46$ & $111 \pm 48$ & 0.63 \\
\hline Crossclamp time (min; mean, SD) & $65 \pm 32$ & $66 \pm 32$ & $64 \pm 30$ & 0.72 \\
\hline No. of grafts (mean, SD) & $3.25 \pm 1.2$ & $3.23 \pm 1.1$ & $3.09 \pm 1.1$ & $0.05^{*}$ \\
\hline History of diabetes & $24.6(61)$ & $25.7(397)$ & $25.3(103)$ & 0.81 \\
\hline History of renal disease & $6.9(17)$ & $5.5(85)$ & $4.2(17)$ & 0.10 \\
\hline Recent MI ( $\leq 31$ days) & $16.3(40)$ & $16.7(254)$ & $18.1(73)$ & 0.42 \\
\hline History of peripheral vascular disease & $20.6(53)$ & $23.4(340)$ & $22.6(92)$ & 0.93 \\
\hline Canadian Heart Assoc classification IV & $25.0(55)$ & $26.7(350)$ & $28.0(97)$ & 0.74 \\
\hline Canadian Heart Assoc classification V & $7.3(16)$ & $7.4(97)$ & $5.2(18)$ & 0.53 \\
\hline Canadian Heart Assoc classification VI & $5.0(11)$ & $5.5(72)$ & $4.9(17)$ & 0.93 \\
\hline
\end{tabular}

$I H C T$, Hematocrit value on entry into the intensive care unit; $S D$, standard deviation; $B S A$, body surface area; $C O P D$, chronic obstructive pulmonary disease; $M I$, myocardial infarction; $C H F$, congestive heart failure; $C A B G$, coronary artery bypass grafting. Calculated percents take into account any missing data. ${ }^{*} p \leq 0.05$ between low HCT and either medium or high HCT.

$\uparrow p \leq 0.05$ between low HCT and high HCT group.

$\$$ History of thrombolysis within 24 hours before $\mathrm{CABG}$.

\$History of aspirin use within 7 days before CABG.

period for adverse myocardial ischemic events is in the immediate perioperative period. ${ }^{9,10}$ Recent data have shown that the period within 1 to 2 hours after protamine administration is associated with the largest number of electrocardiographic changes of ischemia. ${ }^{10}$ The HCT during these first several hours after $\mathrm{CABG}$ represents the sum total of preoperative HCT, hemodilution, blood loss, fluid administration, transfusion therapy, and the transfusion philosophy (transfusion HCT trigger). A representative HCT of that time interval is the HCT on entry to the intensive care unit (IHCT). In a large-scale multicenter study, the relationship between IHCT and adverse clinical outcomes was examined in an effort to answer the question: Is there a "best" IHCT after $\mathrm{CABG}$ ?

\section{Methods}

Patients. The Multicenter Study of Perioperative Ischemia (McSPI) Cardiac Surgery Database was a prospective observational study of 2417 patients in the United States undergoing elective $\mathrm{CABG}$ operations with or without other concurrent cardiac procedures. The study was designed to assess the frequency of adverse postoperative outcomes and to determine the presence of preoperative patient characteristics. ${ }^{11}$ Between 100 and 108 patients were enrolled at each of 24 centers from September 1991 to September 1993 with the use of a standardized questionnaire that has been previously well described. ${ }^{13}$ The volume of intraoperative crystalloid and colloid was measured, as was the use of transfusion (red blood cells [RBCs], platelets, fresh frozen plasma, or cryoprecipitate) during and after the operation. Blood loss was assessed by chest tube drainage.

Postbypass morbidity was defined as (1) low cardiac index $\left(<1.5 \mathrm{~L} / \mathrm{min} \cdot \mathrm{m}^{2}\right)$ or hypotension (arterial systolic pressure $<80 \mathrm{~mm} \mathrm{Hg}$ for $\geq 10$ minutes), or the administration of three or more inotropic agents; (2) the presence of myocardial ischemia by ST segment deviation or the use of intravenous nitroglycerin; (3) hypertension (systolic blood pressure $>180 \mathrm{~mm} \mathrm{Hg}$ for $\geq 10$ minutes), or tachycardia (heart rate $>100$ beats/min for at least 10 minutes).

Adverse events. Adverse postoperative events included Q-wave myocardial infarction (MI), death, renal failure (necessitating hemodialysis), adverse central nervous system outcome (stroke, transient ischemic attack, or stupor/ coma at discharge), or severe left ventricular dysfunction necessitating the use of an intraaortic balloon pump. To 


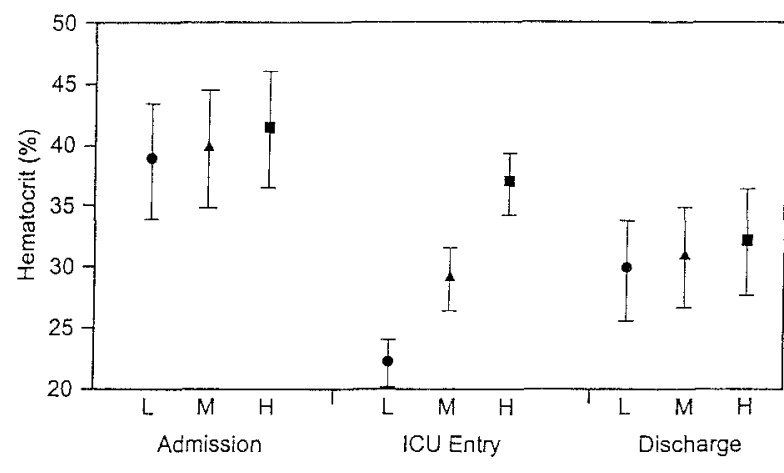

Fig. 1. Level (mean \pm standard deviation) of HCT on admission, on entry to the ICU, and at discharge according to IHCT group. Note that the three subgroups were similar at hospital entry and discharge. $L$, Low HCT ( $\leq 24 \%) ; M$, medium HCT ( $25 \%$ to $33 \%) ; H$, high HCT $(\geq 34 \%)$.

determine the presence of a new Q-wave MI, one preoperative and two postoperative 12-lead electrocardiograms (one collected on postoperative days 0 to 3 and one on days 4 to 10) were analyzed according to Minnesota Code criteria by three electrocardiographers at a central core facility (Ischemia Research and Education Foundation [IREF], San Francisco, Calif.), who were blinded to patients' identities and clinical courses. ${ }^{12}$

HCT. HCT values were recorded at hospital admission, on arrival in the intensive care unit (ICU), and at discharge. The minimum and maximum postoperative values were also noted. The changes in HCT from admission to ICU entry and from ICU entry to discharge were calculated for each patient. Previous studies either considered an $\mathrm{HCT}$ of $25 \%$ as a lower limit or were vague regarding a transfusion trigger. Experimental data suggest that HCT exceeding $33 \%$ may be associated with decreased tissue oxygen delivery. ${ }^{13}$ We thus defined three groups of patients on the basis of IHCT: low $(\leq 24 \%)$, medium $(25 \%$ to $33 \%)$, and high HCT ( $\geq 34 \%)$.

Association of IHCT and intraoperative and postoperative variables. To identify any differences among patients with low, normal, and high IHCT values, we examined preoperative and intraoperative characteristics in each IHCT group. Because IHCT was thought to be a consequence of many intraoperative factors, operative events including blood and fluid loss, postbypass morbidity, and the use of transfusion were carefully examined for the three IHCT groups. Rates of adverse postoperative outcomes were compared across IHCT groups. In addition, these outcomes were examined in subgroups of patients at high risk for adverse events (patients with unstable angina, emergency $\mathrm{CABG}$, reoperation, or a combination of these factors). ${ }^{9,14-17}$ All associations were examined by means of the $\chi^{2}$ test for categoric variables and either general linear modeling or the Kruskal-Wallis test for continuous variables. ${ }^{18}$ All tests were two-tailed.

Multivariate analysis. We limited multivariate analyses to Q-wave $\mathrm{MI}$, because this was the only outcome with a blinded diagnosis. First, we examined the effect of IHCT on risk of $\mathrm{MI}$ after adjustment for single variables. We also examined the effect of site on the relationship between IHCT and MI. Because no variable appeared to confound the relationship between IHCT and MI, we constructed a stepwise logistic regression model using variables previously reported in the literature (age, sex, history of MI, smoking, and reoperation CABG). ${ }^{14-17}$ The entry and stay $\alpha$ level were both set at 0.2 in this analysis (variable will remain if $p \leq 0.2$ and will be removed if $p>$ 0.2 ). All IHCT levels were forced to remain in the model at all times. The Hosmer-Lemeshow test measuring goodness-of-fit was used to validate the final stepwise logistic regression model. ${ }^{19}$

\section{Results}

Patients. Interpretable electrocardiographic and HCT values were available for a total of 2202 patients. The demographic, preoperative, and intraoperative characteristics of the three IHCT groups are presented in Table I. Patients' ages ranged from 28 to 95 years (mean \pm standard deviation: $64.6 \pm$ 10.3 years), with $32 \%$ older than 70 years of age. CABG was performed on an emergency basis in nearly $25 \%$ of cases, and approximately $16 \%$ of patients underwent an additional cardiac procedure, primarily valve repair or replacement.

HCT. Overall, mean HCT at hospital discharge was $25 \%$ lower than at admission (discharge $\mathrm{HCT}=$ $30.8 \% \pm 4.2 \%$, range $=20.1 \%$ to $51.8 \%$; admission HCT $=39.8 \% \pm 4.8 \%$, range $=28.0 \%$ to $54.4 \%$ ). The IHCT had a mean of $29.7 \% \pm 4.7 \%$ and a range of $13.0 \%$ to $47.0 \%$. "Medium" IHCT ( $25 \%$ to $33 \%$ ) was found in $70 \%(n=1544)$ of patients, "low" $(\leq 24 \%)$ in $11 \%(n=248)$, and "high" $(>34 \%)$ in $19 \%(n=410)$. Patients having a high IHCT were likely to have had higher HCT values at both hospital admission and discharge than patients with either low or medium HCT values (Fig. 1). IHCT decreased an average of 16 points from baseline hospital admission values in patients with low IHCT, versus 10 and 6 points in patients with medium and high IHCTs, respectively.

Association between HCT and preoperative variables. Demographic characteristics and medical history for the three IHCT groups are presented in Table I. Patients undergoing reoperation were more likely to have a high IHCT, and patients with a history of anemia, a low IHCT (Table I). Patients in the low IHCT group had a smaller body surface area and a lower mean weight (high IHCT: $81.2 \pm 17.8$ $\mathrm{kg}$; medium IHCT: $80.7 \pm 15.6 \mathrm{~kg}$; low IHCT: $75.9 \pm 13.7 \mathrm{~kg} ; p<0.001$, high vs low). Other preoperative clinical characteristics were similar among the three groups. 
Table II. Volumes of fluid administered, percent of patients given an intraoperative and/or postoperative transfusion, and amount of chest tube drainage in the three IHCT groups

\begin{tabular}{|c|c|c|c|c|c|c|c|c|}
\hline \multirow[b]{2}{*}{$I H C T$} & \multicolumn{4}{|c|}{ Intraoperative } & \multicolumn{3}{|c|}{ Intensive care unit } & \multirow{2}{*}{$\begin{array}{c}\text { Day of } \\
\text { operation } \\
\text { Chest tube } \\
\text { drainage }(\mathrm{ml}) \\
\text { (mean, } S D ; \\
\text { median) }\end{array}$} \\
\hline & $\begin{array}{l}\text { Crystalloid or } \\
\text { colloid (ml) } \\
\text { (mean, SD; } \\
\text { median) }\end{array}$ & $\begin{array}{c}\text { Packed RBCs } \\
\text { and whole blood } \\
\% \text { \% (n) }\end{array}$ & $\frac{\text { Platelets }}{\%(n)}$ & $\begin{array}{c}\text { FFP and } \\
\text { cryoprecipitate } \\
\%(n)\end{array}$ & $\begin{array}{c}\text { Packed RBCs } \\
\text { and whole blood } \\
\%(n)\end{array}$ & $\frac{\text { Platelets }}{\%(n)}$ & $\begin{array}{c}\text { FFP and } \\
\text { cryoprecipitate } \\
\%(n)\end{array}$ & \\
\hline $\begin{array}{c}\mathrm{HCT} \leq 24 \% \\
(n=248)\end{array}$ & $\begin{array}{c}3084 \pm 1476 \\
(2715)\end{array}$ & $50.0(124)$ & $23.0(57)$ & $20.2(50)$ & $66.9(166)$ & $23.0(57)$ & $22.6(56)$ & $\begin{array}{c}774 \pm 534 \\
(620)\end{array}$ \\
\hline $\begin{array}{l}\text { HCT } 25 \%-33 \% \\
\quad(n=1544)\end{array}$ & $\begin{array}{c}2995 \pm 1550 \\
(2800)\end{array}$ & $51.6(797)$ & $15.9(246)$ & $12.0(185)$ & $48.0(741)$ & $14.3(221)$ & $16.5(255)$ & $\begin{array}{c}673 \pm 556 \\
(542)\end{array}$ \\
\hline $\begin{array}{c}\mathrm{HCT} \geq 34 \% \\
\quad(n=410)\end{array}$ & $\begin{array}{c}2654 \pm 1699 \\
(2500)\end{array}$ & $49.5(203)$ & $14.4(59)$ & $10.5(43)$ & $32.2(132)$ & $13.4(55)$ & $16.6(68)$ & $\begin{array}{c}638 \pm 541 \\
(545)\end{array}$ \\
\hline $\mathrm{p}$ Value & 0.01 & 0.71 & 0.01 & 0.001 & $<0.001$ & 0.001 & 0.06 & 0.008 \\
\hline
\end{tabular}

$I H C T$, Hematocrit value on entry into the intensive care unit; $R B C s$, red blood cells; $F F P$, fresh frozen plasma.

Table III. Rates of adverse ischemic outcome in the whole study population sample and in high-risk subgroups stratified by IHCT group

\begin{tabular}{|c|c|c|c|c|c|c|c|c|c|c|c|c|c|c|c|c|}
\hline & \multicolumn{3}{|c|}{ Whole study population } & \multirow{2}{*}{$\begin{array}{c}p \\
\text { Value }\end{array}$} & \multicolumn{3}{|c|}{ Unstable angina } & \multirow{2}{*}{$\begin{array}{c}p \\
\text { Value }\end{array}$} & \multicolumn{3}{|c|}{ Emergency $C A B G$} & \multirow{2}{*}{$\begin{array}{c}p \\
\text { Value }\end{array}$} & \multicolumn{3}{|c|}{ Redo $C A B G$} & \multirow{2}{*}{$\begin{array}{c}p \\
\text { Value }\end{array}$} \\
\hline & $\leq 24 \%$ & $25 \%-33 \%$ & $\geq 34 \%$ & & $\leq 24 \%$ & $25 \%-33 \%$ & $\geq 34 \%$ & & $\leq 24 \%$ & $25 \%-33 \%$ & $\geq 34 \%$ & & $\leq 24 \%$ & $25 \%-33 \%$ & $\geq 34 \%$ & \\
\hline No. & 248 & 1544 & 410 & & 109 & 695 & 193 & & 47 & 333 & 96 & & 23 & 185 & 64 & \\
\hline $\begin{array}{c}\text { Q-wave MI; } \\
\%(\mathrm{n})\end{array}$ & $\begin{array}{l}3.6 \\
(9)\end{array}$ & $\begin{array}{l}5.5 \\
(85)\end{array}$ & $\begin{array}{r}8.3 \\
(34)\end{array}$ & .03 & $\begin{array}{l}5.5 \\
(6)\end{array}$ & $\begin{array}{c}6.6 \\
(46)\end{array}$ & $\begin{array}{c}10.4 \\
(20)\end{array}$ & .16 & $\begin{array}{l}4.3 \\
(2)\end{array}$ & $\begin{array}{r}5.1 \\
(17)\end{array}$ & $\begin{array}{c}7.3 \\
(7)\end{array}$ & .66 & $\begin{array}{l}4.4 \\
(1)\end{array}$ & $\begin{array}{c}6.5 \\
(12)\end{array}$ & $\begin{array}{c}14.1 \\
(9)\end{array}$ & .13 \\
\hline $\begin{array}{l}\text { Severe LV } \\
\text { dysfunc- } \\
\text { tion; \% } \\
\text { (n) }\end{array}$ & $\begin{array}{r}5.7 \\
(14)\end{array}$ & $\begin{array}{c}7.4 \\
(114)\end{array}$ & $\begin{array}{l}11.7 \\
(48)\end{array}$ & .006 & $\begin{array}{l}6.4 \\
(7)\end{array}$ & $\begin{array}{l}9.8 \\
(68)\end{array}$ & $\begin{array}{l}17.1 \\
(33)\end{array}$ & .004 & $\begin{array}{l}12.8 \\
(6)\end{array}$ & $\begin{array}{l}15.6 \\
(53)\end{array}$ & $\begin{array}{l}18.8 \\
(18)\end{array}$ & .63 & $\begin{array}{l}21.7 \\
(5)\end{array}$ & $\begin{array}{l}21.6 \\
(40)\end{array}$ & $\begin{array}{l}32.8 \\
(21)\end{array}$ & .19 \\
\hline $\begin{array}{l}\text { All cause } \\
\text { mortality; } \\
\%(n)\end{array}$ & $\begin{array}{c}5.2 \\
(13)\end{array}$ & $\begin{array}{l}2.6 \\
(40)\end{array}$ & $\begin{array}{r}5.6 \\
(23)\end{array}$ & 0.003 & $\begin{array}{l}3.7 \\
(4)\end{array}$ & $\begin{array}{l}3.3 \\
(23)\end{array}$ & $\begin{array}{l}10.4 \\
(20)\end{array}$ & $<.001$ & $\begin{array}{l}6.4 \\
(3)\end{array}$ & $\begin{array}{c}3.6 \\
(12)\end{array}$ & $\begin{array}{l}10.4 \\
(10)\end{array}$ & .03 & $\begin{array}{l}13.0 \\
(3)\end{array}$ & $\begin{array}{c}5.9 \\
(11)\end{array}$ & $\begin{array}{c}14.1 \\
(9)\end{array}$ & .09 \\
\hline
\end{tabular}

$I H C T$, Hematocrit value on entry into the intensive care unit; $C A B G$, coronary artery bypass grafting; $M I$, myocardial infarction; $L V$, left ventricular.

Association between HCT and transfusion variables. Differences in HCT level from admission to ICU entry were not explained by intraoperative RBC transfusion (Table II). The percentage of patients who received either platelets or fresh frozen plasma was higher in the low IHCT group. Among those who did receive hemostatic products, the median number of units used was not different $(8$ units of platelets per recipient for all IHCT groups, $p=0.55$ ) (fresh frozen plasma low IHCT $=4$ units; median IHCT $=2$ units; high IHCT $=2$ units, $p=$ $0.15)$. Intraoperative crystalloid and colloid administration showed a statistically significant difference (Table II), with the low IHCT group receiving more, but the difference between the low and high IHCT groups of $430 \mathrm{ml}$ is clinically insignificant. Mean chest tube drainage (Table II) was greatest in the low IHCT groups but, again, was not of clinical significance $(136 \mathrm{ml}$ difference between low IHCT and high IHCT). However, a higher proportion of patients with low IHCT had chest tube drainages exceeding $1500 \mathrm{ml}$ on the day of the operation (high $\mathrm{IHCT}=3.4 \%$; median $\mathrm{IHCT}=5.0 \%$; low $\mathrm{IHCT}=$ $8.5 \%, p=0.02)$.

Intraoperative hypertension occurred more often in the low IHCT group, but no differences occurred in postoperative hemodynamics, catecholamine therapy, or vasodilators.

Postoperatively, patients with low IHCT were most likely to receive RBC transfusion. Patients who received non-RBC transfusion in the operating room were more likely to receive a transfusion in the ICU. The proportion of patients returning to the operating room for hemorrhage did not differ between groups (low: $3 \%$; medium: $3 \%$; high: $1 \% ; p=$ $0.23)$.

Association of IHCT with adverse outcome. Postoperative adverse events differed between the IHCT 
Table IV. Effect of IHCT group on risk of MI after adjustment for single variables

\begin{tabular}{lccc}
\hline \multicolumn{1}{c}{ Adjusted variable } & $\begin{array}{c}\text { IHCT } \leq 24 \% ; \\
\text { odds ratio }\end{array}$ & $\begin{array}{c}\text { IHCT 25\%-33\%; } \\
\text { odds ratio }(95 \% \text { CI })\end{array}$ & $\begin{array}{c}\text { IHCT } \geq 34 \% ; \text { odds } \\
\text { ratio }(95 \% \text { CI })\end{array}$ \\
\hline None & 1.00 & $1.55(0.77-3.12)$ & $2.40(1.13-5.10)$ \\
Prior history of MI & 1.00 & $1.52(0.74-3.03)$ & $2.40(1.13-5.10)$ \\
Recent MI & 1.00 & $1.52(0.75-3.06)$ & $2.42(1.14-5.13)$ \\
Gender & 1.00 & $1.56(0.77-3.14)$ & $2.41(1.13-5.11)$ \\
History of unstable angina & 1.00 & $1.71(0.82-3.58)$ & $2.69(1.23-5.93)$ \\
History of angina & 1.00 & $1.71(0.82-3.57)$ & $2.67(1.21-5.87)$ \\
History of CHF & 1.00 & $1.53(0.76-3.08)$ & $2.45(1.16-5.21)$ \\
New York Heart Classification $>3$ & 1.00 & $1.55(0.77-3.11)$ & $2.40(1.13-5.09)$ \\
History of smoking & 1.00 & $1.51(0.75-3.05)$ & $2.24(1.05-4.76)$ \\
Prior PTCA & 1.00 & $1.54(0.76-3.10)$ & $2.38(1.12-5.04)$ \\
History of diabetes & 1.00 & $1.55(0.77-3.12)$ & $2.41(1.13-5.11)$ \\
Age & 1.00 & $1.53(0.76-3.09)$ & $2.44(1.15-5.17)$ \\
Age $>70$ yr & 1.00 & $1.53(0.76-3.09)$ & $2.43(1.15-5.17)$ \\
Reoperation CABG & 1.00 & $1.53(0.76-3.08)$ & $2.34(1.10-4.97)$ \\
$\geq 3$ Vessels bypassed & 1.00 & $1.55(0.77-3.12)$ & $2.40(1.12-5.09)$ \\
Left main disease & 1.00 & $1.55(0.77-3.12)$ & $2.41(1.13-5.11)$ \\
Low ejection fraction $(\leq 30 \%)$ & 1.00 & $1.49(0.70-3.15)$ & $2.12(0.93-4.80)$ \\
CPB time & 1.00 & $1.56(0.77-3.13)$ & $2.42(1.14-5.13)$ \\
CPB time $\geq 120$ min & 1.00 & $1.56(0.77-3.14)$ & $2.41(1.14-5.12)$ \\
\hline
\end{tabular}

IHCT, Hematocrit value on entry into the intensive care unit; $M I$, Q-wave myocardial infarction; $C H F$, congestive heart failure; $P T C A$, percutaneous transluminal coronary angioplasty; $C A B G$, coronary artery bypass grafting; $C P B$, cardiopulmonary bypass. Note: No difference in odds ratios testing different covariates as compared with the model using none.

groups (Table III). Rates of Q-wave MI and severe left ventricular failure were lowest in patients with low IHCT and significantly higher in those with high IHCT $(p=0.03)$. Rates of postoperative central nervous system dysfunction and renal failure did not differ between groups: central nervous system dysfunction: high IHCT $=4.4 \%$, medium $=3.5 \%$, low $=4.4 \%(p=0.59)$; renal failure: high $\mathrm{IHCT}=$ $6.6 \%$, medium $=5.4 \%$, low $=7.7 \%(p=0.29)$. In the whole sample, mortality rates were similar in the low and high IHCT groups. However, high-risk patients tended toward increased all-cause mortality in the high $1 \mathrm{HCT}$ group (high $=8.6 \%$, medium $=$ $3.2 \%$, low $=4.5 \%, p<0.001$ ). In patients with a history of unstable angina, high IHCT was associated with a threefold increase in mortality.

Fig. 2 demonstrates the rates of individual and combined ischemic adverse outcomes in patients stratified by IHCT. In every category of adverse outcome other than death, patients with high IHCT had a greater risk. No other measures of HCT (admission, lowest and highest postoperative, or discharge values) were associated with any adverse outcomes.

Confounding by intraoperative events. To determine whether high IHCT was a surrogate marker for intraoperative morbidity, and thus directly associated with outcome (e.g., patients who were in more clinically unstable condition after bypass may have been more likely to receive a transfusion and thus fall into the high IHCT group and, as well, have more adverse ischemic outcomes), we examined the association between IHCT, postbypass morbidity, adverse ischemic outcome, and the use of RBC transfusion therapy. As expected, patients who had a low cardiac index $(<1.5 \mathrm{~L} / \mathrm{min})$, hypotension, or who received three or more inotropic drugs during the immediate postbypass period were more likely to have an adverse outcome. However, the frequencies of these clinical variables were equally distributed between the IHCT groups (Table I) and they were not independent predictors.

Multivariate analyses. Institution did not confound the relationship between level of IHCT and risk of MI. Logistic regression models of Q-wave MI risk in each IHCT group with covariates showed that none demonstrated different odds ratios (Table IV). Our final stepwise regression model (Table V) showed that IHCT was the most important predictor of Q-wave MI. Patients with high IHCT were more than twice as likely to have a $\mathrm{Q}$-wave $\mathrm{MI}$ as patients with low IHCT $(p=0.04)$ and 1.4 times more likely than patients with a medium IHCT $(p=0.31)$. In additional models including intraoperative variables such as (1) RBC transfusion recuirements (2) postbypass signs of hemodynamic instability (e.g., hypo- 
Table V. Final stepwise logistic regression model odds ratios (OR) and $95 \%$ confidence intervals (CI) for prediction of postoperative $Q$-wave $M I$

\begin{tabular}{|c|c|c|}
\hline Variables in model & OR $(95 \% C I)$ & $p$ Value \\
\hline \multicolumn{3}{|l|}{ IHCT group } \\
\hline$\leq 24 \%$ & 1 & \\
\hline $24 \%-33 \%$ & $1.44(0.71-2.92)$ & 0.31 \\
\hline$\geq 34 \%$ & $2.22(1.04-4.76)$ & 0.04 \\
\hline \multicolumn{3}{|l|}{ Age $(y r)$} \\
\hline$<60$ & 1.00 & \\
\hline $60-70$ & $1.33(0.83-2.14)$ & 0.24 \\
\hline$>70$ & $1.61(0.98-2.64)$ & 0.06 \\
\hline \multicolumn{3}{|l|}{ Sex } \\
\hline Male & 1.00 & \\
\hline Female & $1.38(0.90-2.11)$ & 0.14 \\
\hline \multicolumn{3}{|l|}{ History of MI } \\
\hline No & 1.00 & \\
\hline Yes & $1.88(1.27-2.8)$ & 0.002 \\
\hline \multicolumn{3}{|l|}{ History of smoking } \\
\hline No & 1.00 & \\
\hline Yes & $1.65(1.06-2.6)$ & 0.03 \\
\hline \multicolumn{3}{|l|}{ Reoperation } \\
\hline \multicolumn{3}{|l|}{ CABG } \\
\hline No & 1.00 & \\
\hline Yes & $1.35(0.83-2.21)$ & 0.23 \\
\hline
\end{tabular}

$O R$, Odds ratio; $C l$, confidence intervals; $M I$, myocardial infarction; $I H C T$ hematocrit value on entry into the intensive care unit; $C A B G$, coronary artery bypass grafting.

tension, low cardiac index), and (3) site, the magnitude and significance of these odds ratios for IHCT did not change.

\section{Discussion}

Patients and adverse events. Our results demonstrate that IHCT level after CABG is significantly related to adverse outcome. In multivariate analysis that examined a wide variety of possible predictors, IHCT was the most significant independent predictor of Q-wave MI. This finding suggests that anemia is well tolerated with respect to MI.

Confounding variables. The finding that low IHCT was associated with fewer ischemic events was unexpected. Therefore it was of paramount importance that confounding variables be examined. Transfusion and fluid administration were not greatly different between groups, and no independent relationship was detected between transfusion or fluid administration and MI. Although crystalloid fluid administration did statistically differ between low and high IHCT groups, the difference in volume $(430 \mathrm{ml})$ was not clinically important. Although lower IHCT did appear to affect the use of hemostatic components and to be associated with increased bleeding, no relationship was identified

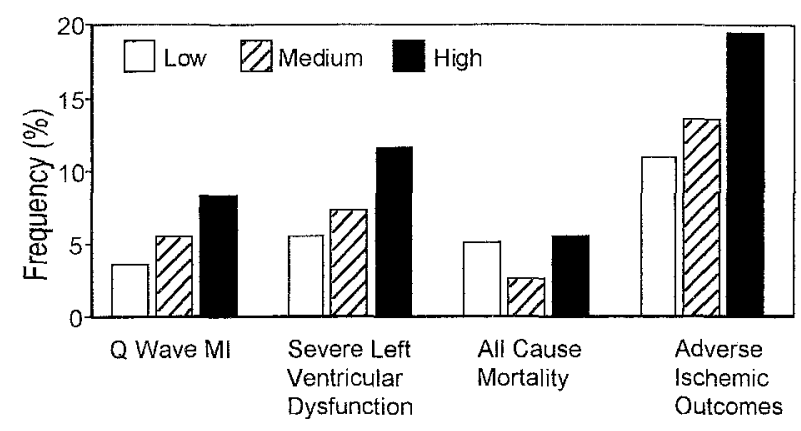

Fig. 2. Frequency of Q-wave MI, severe left ventricular dysfunction (intraaortic balloon pump use), all-cause mortality, and combined (all three) adverse ischemic outcome by the IHCT group. Low, HCT $\leq 24 \%$; Medium, HCT $25 \%$ to $33 \% ; H i g h$, HCT $\geq 34 \%$.

between the use of these blood components and MI rates. Decreasing the value of the cut point for low HCT below or above $24 \%$ did not alter our findings.

If more severely ill patients (preoperatively or intraoperatively) were preferentially maintained at a higher IHCT (e.g., through transfusion, hemoconcentration, fluid restriction), then the association between high IHCT and adverse outcome could be easily explained. Therefore we examined whether patients with clinical signs of postbypass morbidity (low cardiac index, hypotension, hypertension, tachycardia, ischemia, or requirement for inotropic medications or intravenous nitroglycerin) were more likely to have higher IHCT levels. These seriously ill patients were equally distributed among the three IHCT groups. Thus perioperative morbidity was not a confounder.

Limitations. Limitations of our study include the definition of outcome. New $Q$ waves were chosen as a very strict and exclusive definition of MI. If other, perhaps more liberal definitions of MI (e.g., creatine kinase MB, troponin, myoglobin, or echocardiographic findings) had been used, the frequency of these events by IHCT group may well have been different. No association was found between IHCT and other ischemic adverse outcomes such as stroke and renal failure. In addition, our study did not examine fibrinolytic state, platelet number, or function, and HCT was examined at only five time points. More HCT values with extensive hematologic correlates could potentially provide more information concerning cause and effect for the relationship found.

Prior work and potential causes. Prior research in animal models of anemia with both acute and 
chronic coronary obstruction has been performed. $^{20-22}$ Ischemia occurs across a wide range of HCT values from $17 \%$ to $42.5 \% .^{20-22}$ Previous case reports and single-center studies support our findings that anemia alone does not increase the risk of MI after CABG. ${ }^{1}$ In two studies of eight and 224 patients, HCT levels did not affect myocardial lactate flux, a measure of ischemia. ${ }^{23,24}$ In a small study of 14 patients, the oxygen content of the coronary sinus did not change with either hemodilution (to $23 \%$ ) or subsequent transfusion to $34 \% .^{25}$ A case report of a patient with an HCT level of $5 \%$ described diffuse myocardial dysfunction, relieved with transfusion, but no postoperative $\mathrm{MI}^{2}$ In our study, even in patients with IHCT levels between $13 \%$ and $18 \%(n=13)$, no $\mathrm{Q}$-wave MI or ventricular dysfunction occurred, nor were there any deaths.

Perioperative MI and dysfunction are likely the result of multiple causes. ${ }^{9}$ An increased IHCT level may precipitate ischemic injury via several mechanisms: (1) Increased blood viscosity may require additional work by the myocardium, as well as decreasing tissue oxygen delivery. ${ }^{16}$ (2) Shear forces between the vessel walls and the blood increase as the concentration of red blood cells increases. In addition, platelets exposed to these greater shear forces are more likely to be activated, and increased lateral platelet migration exists. ${ }^{26}$ Therefore the number of interactions per unit time between platelets and the endothelial walls increases. ${ }^{27}$ These interactions between altered endothelium and activated platelets may be important. ${ }^{28}$ (3) With increased IHCT, the availability of nitric oxide, an inhibitor of platelet and neutrophil binding to endothelial cells, ${ }^{29}$ may be decreased. (4) Liberated hemoglobin taken up by endothelial cells increases free radical production, ${ }^{30}$ perhaps worsening endothelial dysfunction.

In conclusion, on the basis of this study of 2202 patients, low IHCT $(<24 \%)$ at the conclusion of CABG operations appears to protect against $Q$ wave MI. Therefore our data do not support arbitrary transfusion of $\mathrm{RBC}$ products to increase oxygen-carrying capacity after CABG. Furthermore, allowing a low IHCT to occur after CABG might decrease the morbidity and cost associated with transfusion and also preserve a scarce resource (allogeneic blood). Future randomized prospective trials will be required to discover the mechanisms involved, as well as to examine associations between IHCT and creatine kinase MB or ischemia by ST-T wave analysis.
We acknowledge the assistance of Sonja Kapitan, MPH, in collecting and entering data, as well as the excellent secretarial assistance of Donna J. Rowe, BA. We also thank Long Ngo and Reg Parks for additional statistical insights.

\section{REFERENCES}

1. Spence RK, Alexander JB, Del Rossi AJ, Cernaianu AD, Cilley J Jr, Pello MJ, et al. Transfusion guidelines for cardiovascular surgery: lessons learned from operations in Jehovah's Witnesses. J Vasc Surg 1992;16:825-31.

2. Cohen E, Neustein SM, Silvay G. Profound anemia following cardiac surgery. J Cardiothorac Vasc Anesth 1993;7:721-3.

3. Donahue JG, Muñoz A, Ness PM, Brown DE Jr, Yawn DH, McAllister HA Jr, et al. The declining risk of post-transfusion hepatitis C-virus infection. N Engl J Med 1992;327:369-73.

4. Goodnough LT, Johnston MF, Toy PT. The variability of transfusion practice in coronary artery bypass surgery. JAMA 1991;265:86-90.

5. Stover EP, Siegel LC, Parks R, McSPI Research Group. Variability in transfusion practice for coronary artery bypass surgery persists despite national consensus guidelines. Anesthesiology 1998;88:327-33.

6. Surgenor DM, Wallace EL, Hao SH, Chapman RH. Collection and transfusion of blood in the United States 1982-1988. N Engl J Med 1990;322:1646-51.

7. Johnson RG, Thurer RL, Kruskall MS, Sirois C, Gervino EV, Critchlow J, et al. Comparison of two transfusion strategies after elective operations for myocardial revascularization. J Thorac Cardiovase Surg 1992;104:307-14.

8. Cosgrove DM, Loop FD, Lytle BW, Gill CC, Golding LR, Taylor PC, et al. Determinants of blood utilization during myocardial revascularization. Ann Thorac Surg 1985;40:380-4.

9. Mangano DT. Perioperative cardiac morbidity. Anesthesiology 1990;72:153-84.

10. Jain U, Wallis DE, Moran JF. Significance of electrocardiographic ST elevation during coronary artery bypass surgery. Anesth Analg 1994;78:638-43.

11. Mathew JP, Parks R, Savino JS, Friedman AS, Koch C, Mangano DT, et al. Atrial fibrillation following coronary artery bypass graft surgery: predictors, outcomes, and resource utilization. JAMA 1996;276:300-6.

12. The Multicenter Study of Perioperative Ischemia, McSPI Research Group. Effects of acadesine on morbidity and mortality following coronary artery bypass graft surgery. Anesthesiology 1995;83:685-73.

13. Messmer K, Lewis DH, Sunder-Plassmann L, Klovekorn WP, Mendler N, Holper K. Acute normovolemic hemodilution. Eur Surg Res 1972;4:55-70.

14. Royster RL, Butterworth JF, Prough DS, Johnston WE Thomas JL, Hogan PE, et al. Preoperative and intraoperative predictors of inotropic support and long-term outcome in patients having coronary artery bypass grafting. Anesth Analg 1991;72:729-36.

15. O'Connor GT, Plume SK, Olmstead EM, Coffin LH, Morton JR, Maloney CT, et al. Multivariate prediction of inhospital mortality associated with coronary artery bypass graft surgery. Circulation 1992;85:2110-8.

16. Higgins TL, Estafanous FG, Loop FD, Beck GJ, Blum JM, Paranandi L. Stratification of morbidity and mortality outcome by preoperative risk factors in coronary artery bypass patients. JAMA 1992;267:2344-8. 
17. Tuman KJ, McCarthy RJ, March RJ, Najafi H, Ivankovich AD Morbidity and duration of ICU stay after cardiac surgery: a model for preoperative risk assessment. Chest 1992;102:36-44.

18. Lehmann EL. Nonparametrics-statistical methods based on ranks. San Francisco: Holden-Day; 1975

19. Hosmer DW, Lemeshow S. Applied logistic regression. New York: John Wiley; 1989.

20. Case RB, Berglund E, Sarnoff SJ. Ventricular function. VII. Changes in coronary resistance and ventricular function resulting from acutely induced anemia and the effect thereon of coronary stenosis. Am J Med 1955;18:397-405.

21. Yoshikawa H, Powell WJ, Bland JH, Lowenstein E. Effect of acute anemia on experimental myocardial ischemia. Am J Cardiol 1973;32:670-8.

22. Most AS, Ruocco NA, Gewirtz H. Effect of a reduction in blood viscosity on maximal myocardial oxygen delivery distal to a moderate coronary stenosis. Circulation 1986;74:1085-92.

23. Doak GJ, Hall RI. Does hemoglobin concentration affect perioperative myocardial lactate flux in patients undergoing coronary artery bypass surgery? Anesth Analg 1995;80:910-6.

24. Mathru M, Kleinman B, Blakeman B, Sullivan H, Kumar P, Dries DJ. Myocardial metabolism and adaptation during extreme hemodilution in humans after coronary revascularization. Crit Care Med 1992;20:1420-5.

25. Kim YD, Katz NM, Ng L, Nancherla A, Ahmed SW, Wallace RB. Effects of hypothermia and hemodilution on oxygen metabolism and hemodynamics in patients recovering from coronary artery bypass operation. J Thorac Cardiovasc Surg 1989; $97: 36-42$.

26. Reimers RC, Sutera SP, Joist JH. Potentiation by red blood cells of shear-induced platelet aggregation: relative importance of chemical and physical mechanisms. Blood 1984;64: $1200-6$.

27. Turitto VT, Weiss HJ. Rheological factors influencing platelet interaction with vessel surfaces. J Rheol 1979;23:735-49.

28. Tsao PS, Aoki N, Lefer DJ, Johnson G, Lefer AM. Time course of endothelial dysfunction and myocardial injury during myocardial injury and reperfusion in the cat. Circulation 1990;82:1402-12.

29. Radomski MW, Moncada S. The biological and pharmacological role of nitric oxide in platelet function. In: Authi KS, editor. Mechanisms of platelet activation and control. New York: Plenum; 1993, p. 251-64.

30. Balla J, Jacob HS, Balla G, Nath K, Eaton JW, Vercellotti GM. Endothelial-cell heme uptake from heme proteins: induction of sensitization and desensitization to oxidant damage. Proc Natl Acad Sci U S A 1993;90:9285-9.

\section{Appendix 1}

Participating $M c S P I$ institutions and investigators. Anil Aggarwal, MD, VA Medical Center, Milwaukee, Wis.; Wayne H. Bellows, MD, Gary Roach, MD, Kaiser-Permanente Medical Center, San Francisco, Calif.; Simon Body, MD, Rosemarie Maddi, MD, Brigham and Women's Hospital, Boston, Mass.; Randall Clark, MD, Patrick E. Curling, MD, Salwa Shenaq, MD, Baylor College of Medicine, Houston, Tex.; Mark E. Comunale, MD, Beth Israel Hospital, Boston, Mass.; Michael N. D'Ambra, MD, Massachusetts General Hospital. Boston, Mass.; Judith Fabian, MD, Richard Wolman, MD, Medical College of Virginia, Richmond, Va.; Richard Fine, MD, Onofrio Patafio, MD, Cornell University Medical Center, New York, N.Y.; Arnold S. Friedman, MD, Cedars-Sinai Medical Center, Los Angeles, Calif.; Mark Goldstein, MD, Stephen Slogoff, MD, Texas Heart Institute, Houston, Tex.; Marc Kanchuger, MD, Katherine E. Marschall, MD, New York University Medical Center, New York, N.Y.; Colleen Koch, MD, Norman J. Starr, MD, The Cleveland Clinic Foundation, Cleveland, Ohio; William Lell, MD, University of Alabama at Birmingham, Birmingham, Ala.; Joseph P. Mathew, MD, Yale University School of Medicine, New Haven, Conn.; Christina Mora Mangano, MD, James G. Ramsay, MD, Emory University School of Medicine, Atlanta, Ga,; Gerard M. Ozanne, MD, VA Medical Center, San Francisco, Calif,; Allan F. Ross, MD, University of lowa, lowa Ciiy, Iowa; Joseph S. Savino, MD, University of Pennsylvania, Philadelphia, Pa.; Bruce Spiess, MD, University of Washington, Seattle, Wash.; Thomas E. Stanley, MD, Duke University Medical Center, Durham, N.C.; E. Price Stover, MD, Lawrence C. Sigel, MD, Stanford University Medical Center, Stanford, Calif.; Kenneth J. Tuman, MD, RushPresbyterian-St. Luke's Medical Center, Chicago, Ill.; Joyce Wahr, MD, University of Michigan, Ann Arbor, Mich.; Winnie Ruo, MD, Mark Trankina, MD, University of Chicago, Chicago, Ill.

\section{Appendix 2}

Core analysis group. Director: Dennis T. Mangano, PhD, MD. Data Management/Statistical Analysis: Catherine Ley, PhD, Long Ngo, MS, Fong Liu, MSPH, Elizabeth Li, MS. Clinican Design Consultant: Gerard M. Ozanne, MD. Electrocardiographic Analysis: Uday Jain, PhD, MD, Adam Zhang, MD, Vladimir Titov, MD, PhD, Tatiana Titov, MD, PhD, Marilena Mirica, MD. Editorial Assistants: Winnifred von Ehrenburg, Diane Beatty, Mark Riddle. 